Erratum

\title{
Correction: Construction of a multiplex mutation hot spot PCR panel: the first step towards colorectal cancer genotyping on the GS Junior platform
}

\author{
Bálint Péterfia ${ }^{1,2}$ \\ 1. 2nd Department of Internal Medicine, Semmelweis University, Budapest, Hungary; \\ 2. Molecular Medicine Research Group, Hungarian Academy of Sciences, Budapest, Hungary \\ $\square$ Corresponding author. \\ (c) Ivyspring International Publisher. This is an open access article distributed under the terms of the Creative Commons Attribution (CC BY-NC) license \\ (https://creativecommons.org/licenses/by-nc/4.0/). See http://ivyspring.com/terms for full terms and conditions.
}

Published: 2018.07.01

Corrected article: J Cancer 2017; 8(2):162-173. doi:10.7150/jca.16037.

The Acknowledgments section in our paper [1] was incomplete and should instead read as follows: The results published here are in whole or part based upon data generated by The Cancer Genome Atlas managed by the NCI and NHGRI (http://cancergenome.nih.gov). The TCGA data analyzed here are available through dbGAP, accession phs000178.v9.p8 (http://www.ncbi.nlm.nih.gov/projects/gap/cgi-bin/study.cgi?study_id= phs000178.v9.p8).

The authors apologize for the incomplete Acknowledgments.

\section{References}

1. Péterfia B, Kalmár A, Patai ÁV, Csabai I, Bodor A, Micsik T, Wichmann B, Egedi K, Hollósi P, Kovalszky I, Tulassay Z, Molnár B. Construction of a multiplex mutation hot spot PCR panel: the first step towards colorectal cancer genotyping on the GS Junior platform. J Cancer 2017; 8(2):162-173. doi:10.7150/jca.16037. 